\title{
An Introductory Guide to Drug Reference Sources
}

\author{
Erin M. Watson
}

\begin{abstract}
A huge number of drug reference sources exist. For the librarian new to the drug information field, choosing the appropriate source to answer a reference question can be difficult. This paper presents some common drug reference questions and some of the American, British, and Canadian tools best suited to answering them.
\end{abstract}

KEYWORDS. Reference work, drug information, bibliographies

\section{INTRODUCTION}

Librarians new to answering drug reference questions may feel a little panicky when they are asked to find the solubility of one drug or the pediatric dosage for another. MEDLINE, the standby of medical librarians, does not often provide answers to these "quick reference" questions. A huge number of drug reference sources exist, but which ones should be used to answer which questions? The following is an attempt to present some of the most common types of questions, and some of the major American, British, and Canadian drug reference

Erin M. Watson, MLIS (e.watson@usask.ca) is Information Services Librarian,

Health Sciences Library, University of Saskatchewan,

107 Wiggins Road, Saskatoon, SK S7N 5E5.

Published in: Medical Reference Services Quarterly, Vol. 25(1) Spring 2006

(C) 2006 by The Haworth Press, Inc. 
tools that can be used to answer them. The information about the most current edition of each tool is provided, and if it is available online, this is indicated as well. In many cases, the scope of the titles listed may be similar; therefore, it may be necessary to consult only one to find the needed information. Special features of each title have been highlighted to show which title would be the best choice. This guide is meant only to be a starting place for librarians unfamiliar with drug reference resources; it is by no means exhaustive.

Much more information can be found in all of the resources listed at the end of this article, but especially in Bonnie Snow’s excellent book, Drug Information: A Guide to Current Resources.

\section{HOW IS A PARTICULAR DISEASE TREATED?}

Therapeutics is the study of the treatment of disease. All of the textbooks below are organized by disease or disorder rather than by the drugs used to treat them. They provide an overview (etiology, pathophysiology, epidemiology, etc.) of the disease or disorder and a discussion of treatment options. In presenting this information, all titles cite the journal literature extensively.

Koda-Kimble, Mary Anne, ed. Applied Therapeutics: The Clinical Use of Drugs. 8th ed. Philadelphia: Lippincott Williams \& Wilkins, 2005.

This is a large comprehensive textbook. It is organized in a case study format; questions and answers related to diagnosis and treatment are presented.

DiPiro, Joseph T., ed. et al. Pharmacotherapy: A Pathophysiologic Approach. 6th ed. New York: McGraw-Hill, 2005.

This is another comprehensive textbook. Many chapters provide a discussion of “pharmacoeconomic considerations” (i.e., costs of treatment) and “evaluation of therapeutic outcomes” (i.e., ways to determine the effectiveness of the treatment). 
Gray, Jean. ed. Therapeutic Choices. 4th ed. Ottawa: Canadian Pharmacists Association, 2003.

This is a smaller textbook, but one that focuses on the Canadian environment. Most chapters provide a chart that compares adverse effects, dosages and costs of different treatment options. Each chapter includes a list of suggested readings.

Berardi, Rosemary, ed. Handbook of Nonprescription Drugs: An Interactive Approach to Self-Care. 14th ed. Washington: American Pharmaceutical Association, 2004.

This large text focuses on the use of over-the-counter drugs for treatment, but describes situations that require referral to a physician. All chapters contain patient education information.

Repchinsky, Carol Ann, ed. Patient Self-Care: Helping Patients Make Therapeutic Choices. 1st ed. Ottawa: Canadian Pharmacists Association, 2002.

The format of this title is very similar to Therapeutic Choices, but the focus is on overthe-counter treatments. It provides suggested readings and patient information for each topic.

\section{IS A PARTICULAR DRUG APPROVED FOR USE IN THE U.S., THE U.K., OR ELSEWHERE?}

Pharmacopoeias are the official and comprehensive lists of drugs available for use in a particular country and so are the best source to determine definitively that a drug is approved in a particular country. They also provide information on the standards of purity and physical and chemical properties of drugs.

The United States Pharmacopeia/National Formulary. (USP 28-NF 23) Rockville, Maryland: United States Pharmacopeial Convention Inc., 2004. Annual. Available online and on CD-ROM from <http://www.usp.org>.

The first section, the pharmacopoeia, provides standards of purity for drugs approved for use in the United States. The second section, the formulary, provides similar information for 
botanicals and excipients (substances used to improve the form or consistency of a drug formulation).

British Pharmacopoeia. London: Published for the General Medical Council by the Pharmaceutical Press. 2004. Annual. Available online from <http:// www.britpharm.org>.

This title provides the physical and chemical properties and standards of purity for the drugs in use in the United Kingdom.

Canada does not have an official pharmacopoeia.

Sweetman, Sean C, ed. Martindale: The Complete Drug Reference. 33rd ed. London: Pharmaceutical Press, 2002. Available online and on CD-ROM from $<$ http://www.pharmpress.com>.

Martindale is not an official pharmacopoeia (its former subtitle was actually "the extra pharmacopoeia”), but it is an excellent all-round reference. It lists the proprietary preparations (brand names) from around the world for each drug, and so is an excellent place to confirm the generic name of a drug, or to find out where a drug is approved for use. It provides several journal references for each use and adverse effect, as well as the chemical formula for each drug.

\section{WHAT DOSAGE SHOULD BE GIVEN? WHAT ARE THE CONTRAINDICATIONS, ETC.?}

\section{Information Provided by Manufacturers}

The following are composed primarily of information provided by manufacturers. They are good sources of information about drug dosage, composition, and adverse effects. Because manufacturers choose whether to submit their information to these publishers (and generally must pay a fee to do so), not all approved drugs are included.

Physicians' Desk Reference: PDR. 58th ed. Montvale, New Jersey: Medical Economics Company, 2004. Annual. Available online from <http://www.pdr. net>. 
This is a collection of Food and Drug Administration-approved manufacturers' package inserts for prescription drugs in use in the United States. It includes a drug identification section with photographs of individual drugs.

Repchinsky, Carol Ann, ed. Compendium of Pharmaceuticals and Specialties. 39th ed. Toronto: Canadian Pharmacists Association, 2004. Annual. Available online from $<$ http://www.pharmacists.ca $>$.

Also known as the CPS, the bulk of this work is composed of Health Canada-approved product information (for both patients and clinicians) written by drug manufacturers. However, the editors have also written evidence-based drug monographs, usually about classes of drugs (e.g., systemic corticosteroids) rather than individual products. This is a large work with several sections; others are a therapeutic guide that shows which drugs are used for which conditions, a drug identification section with photographs of individual drugs, and a CLIN-Info section which contains quick reference charts on various topics, such as food-drug interactions and prevention of bacterial endocarditis.

Repchinsky, Carol Ann, ed. Compendium of Self-Care Products. Ottawa: Canadian Pharmacists Association, 2002.

This is the over-the-counter equivalent to the CPS. Again, it is composed mainly of manufacturers’ monographs, with some general monographs written by the Canadian Pharmacists Association. There are also numerous charts that compare drugs with similar functions. Patient information (taken from the package inserts dispensed with the drug) is also provided.

Physicians’ Desk Reference for Nonprescription Drugs and Dietary Supplements. 24th ed. Montvale, New Jersey: Medical Economics Company, 2003.

This title is similar to the $P D R$, but covers over-the-counter products. It contains an index of drugs listed by active ingredient and a drug identification guide with photographs of drugs.

\section{Information Provided by Third Parties}


The titles below are all composed of information written by third parties. They discuss drugs by generic name rather than by brand name. All provide information on indications (uses), dosages, contraindications and adverse effects.

USP Di. Volume 1: Drug Information for the Health Professional. 25th ed. Rockville, Maryland: United States Pharmacopeial Convention Inc., 2005. Available online from $<$ http://usp.org $>$.

This is part of the "Dispensing Information" section of the United States Pharmacopoeia. (Volume 2 provides patient information, while Volume 3 provides information on legal issues such as generic substitution, handling, and distribution requirements.) It is now published by Micromedex Corporation and written by the Micromedex and USP staff. The USP Di volume 1's drug descriptions begin with the general drug class and then provide information on specific drugs. These include information on "off-label” use (use of the drugs in ways other than those for which they have been approved) as well as on pharmacology and pharmacokinetics (how the drug is absorbed and eliminated by the body), interactions, and brand names. They also include extensive references to journal literature.

AHFS Drug Information. Bethesda, Maryland: American Society of Health-System Pharmacists, 2004. Annual. Available online from <http://www.statref. com>.

AHFS (American Hospital Formulary Service) Drug Information is intended for use by hospital pharmacists. Five hundred experts prepare the extensive drug monographs. These include information on off-label uses, and a brief discussion of pharmacology and pharmacokinetics. They also provide a brief listing of available products and doses. Each monograph provides extensive references to journal literature.

British National Formulary. London: British Medical Association, 2005. Semiannual.

The British National Formulary is the pocket-sized companion to the British Pharmacopoeia and provides a brief description of the drugs listed there. Entries include the cost of available formulations.

Mosby’s Drug Consult. 15th ed. St. Louis: Mosby, 2005. Annual. Available online from $<$ http://www.statref.com>. 
Most drug monographs provide the pronunciation of the generic name, the date when the drug was approved by the Federal Drug Administration and a list of foreign brand names. They also include off-label uses, interactions, pharmacokinetics and cost of selected formulations. This resource includes a drug identification section with a list of drug imprints and photographs of individual drugs. It also provides tables that compare drugs with a similar function by dosage and drug interactions.

Drug Facts and Comparisons. St. Louis: Facts and Comparisons, 2005.

As is evident in the title, this tool compares drugs to one another. This comparison is based on their dosage form (capsules, elixirs, transdermal patches, etc.), dosage, cost and mechanism of action (i.e., how they have their effect). The information provided is taken from both journal literature and manufacturer information.

Fillups, Norman F., and Fillups, Shirley M. eds. American Drug Index. 49th ed. Facts and Comparisons, 2005. Annual.

This title is unlike the others in this section. Instead of focusing on dosage, contraindications, etc., this pocket-sized book lists ingredients for both overthe-counter and prescription formulations available in the United States. For generic names, the pronunciation is usually provided, followed by a listing of brand names.

\section{WHICH DRUGS INTERACT WITH EACH OTHER?}

Zucchero, Frederic J.; Hogan, Mark J.; Sommer, Christine D.; and Curran, John Patrick. Evaluations of Drug Interactions (EDI). First DataBank. Bimonthly updates.

This is a loose-leaf service and is updated more often than any of the other titles listed in this section. Interactions are ranked on a scale of 1 to 4 based on the severity, the number of times they have occurred, and the evidence documenting these effects. References are provided to appropriate journal literature. This title is also available in a condensed format: Pocket Guide to Evaluations of Drug Interactions (of which the fifth edition was published in 2004). The Pocket Guide provides brief information about some of the most significant 
interactions described by the larger title, but refers reader to the appropriate section of $E D I$ for more information.

Hansten, Philip D., and Horn, John R. Drug Interactions Analysis and Management. St. Louis: Facts and Comparisons. Quarterly updates.

Another loose-leaf service, this title provides the level of risk, the mechanism, a brief discussion of pertinent cases, options for management, and a list of journal references for each drug interaction.

Stockley, Ivan H. Stockley's Drug Interactions: A Sourcebook of Interactions, Their Mechanisms, Clinical Importance and Management. 6th ed. London: Pharmaceutical Press, 2002.

This title summarizes the risk of each drug combination in one or two sentences, and then provides a brief overview of the clinical evidence, the mechanism of the interaction, and its importance and management. Each entry concludes with a list of references.

Tatro, David S. ed. Drug Interaction Facts 2005. St. Louis: Facts and Comparisons, 2005. Annual.

Each drug combination is given a significance rating (on a scale of 1 to 5) based on its severity and the amount of evidence which indicates this effect. Both classes of drugs and individual drugs are listed. This title is visually very easy to interpret, but contains fewer references to journal articles than does Stockley's.

Meyler's Side Effects of Drugs. 14th ed. Amsterdam: Excerpta Medica, 2000. Quadrennial. Updated by the Side Effects of Drugs Annual.

This title provides a summary of, and references to, worldwide journal articles on adverse effects and interactions of both groups of drugs (e.g., antipyretic analgesics) and individual drugs. Indexes allow users to search by drug name or by adverse effect. Although this is a large book, because it covers both adverse effects and interactions, it provides less coverage of individual interactions than do the other titles discussed here. 


\section{WHAT IS THE MECHANISM OF ACTION OF A PARTICULAR DRUG? (HOW DOES A PARTICULAR DRUG WORK?)}

Hardman, Joel G., and Limbird, Lee E. eds. Goodman \& Gilman's the Pharmacological Basis of Therapeutics. 10th ed. New York: McGraw-Hill, 2001. Available online from $<$ http://www.statref.com>.

This large text is the best place to look for information on how drugs work, how quickly they are absorbed and how long they remain in the body, their chemical structure, and their adverse effects. Some chapters focus on a particular disease (e.g., "Drugs Effective in the Therapy of the Epilepsies"), while others are organized by drug action (e.g., "Muscarinic Receptor Agonists and Antagonists"). Each chapter provides extensive references to journal literature.

\section{WHAT IS THE BOILING POINT, SOLUBILITY, ETC., OF A PARTICULAR DRUG?}

O’Neil, Maryadele J., ed. The Merck Index: An Encyclopedia of Chemicals, Drugs, and Biologicals. 13th ed. Whitehouse Station, New Jersey: Merck, 2001. Available on CD-ROM and online from $<$ http://www.merckbooks. com>.

This is a very good source of information about the physical properties (melting point, molecular weight, etc.), structure and the chemical properties (reaction characteristics) of drugs and other chemicals. There are also many references to journal articles on the isolation and purification of each drug.

Remington, the Science and Practice of Pharmacy. 21st ed. Baltimore, Maryland: Lippincott, Williams and Wilkins, 2005. Quinquennial.

Written by staff of the University of the Sciences in Philadelphia, this textbook provides one-chapter summaries of topics such as solubility, thermodynamics, long-term care, pharmacy ethics, prolonged-action pharmaceuticals, etc. It is a good place to look for physical properties of drugs and formulas for pharmacokinetic calculations, compounding, etc. While it does give a short description of the uses and adverse effects of various drugs, other sources provide better information. 


\section{CAN A PARTICULAR DRUG BE TAKEN DURING PREGNANCY?}

Briggs, Gerald G.; Freeman, Roger K.; and Yaffe, Sumner J. Drugs in Pregnancy and Lactation: A Reference Guide to Fetal and Neonatal Risk. 6th ed. Philadelphia: Lippincott Williams \& Wilkins, 2002. Available online from OVID.

This title provides an overall safety rating for each drug, followed by a summary of the journal literature on the possible risk to the fetus and to the nursing child.

\section{WHICH DRUGS CAN BE ADMINISTERED TOGETHER EITHER BY SYRINGE OR INTRAVENOUSLY?}

Trissel, Lawrence A. Handbook on Injectable Drugs. 13th ed. Bethesda, Maryland: American Society of Health-System Pharmacists, 2005. Available on CD-ROM and online from $<$ http://www.ashp.org $>$.

This book reports results of research done on the physical incompatibility of various drugs when administered together intravenously or by syringe. It is important to note that the scope of this title is not the drug interactions that may occur when two drugs are given to a patient at the same time, but rather the physical compatibility of the two drugs in solution, i.e., whether there is some form of decomposition when the two mix.

\section{WHAT IS THE EFFECT OF A PARTICULAR HERBAL PRODUCT ON A PARTICULAR DISORDER/CONDITION?}

There are a huge number of herbal references. All of the ones listed below describe the uses, dosages, adverse effects, and possible interactions of the various herbal medicines.

Blumenthal, Mark. ed. Complete German Commission E Monographs: Therapeutic Guide to Herbal Medicines. Austin, Texas: American Botanical Council, 1998. 
This is the English translation of monographs written by the Commission E (Kommission E), a committee charged by the German government with investigating the efficacy and safety of herbal drugs. Herbs are listed as approved or unapproved. When herbs have not been approved a reason for this is given. The drawback to this text is that these monographs were written some time ago (1983-1995), and so new research has not been included. No references to the literature used to make the approval decisions have been provided.

PDR for Herbal Medicines. 3rd ed. Montvale, New Jersey: Medical Economics Company, 2004.

Unlike the PDR titles discussed previously, this is not composed of Food and Drug Administration-approved product inserts, for the simple reason that the Food and Drug Administration does not allow herbal manufacturers to make claims about the efficacy of their products in the treatment of particular conditions. Instead, this title summarizes the findings of Germany's Commission $\mathrm{E}$ as well as of literature reviews conducted by the PhytoPharm U.S. Institute of Phytopharmaceuticals. Each entry indicates whether the herb is unproven, used in homeopathic, Chinese, or Indian medicine, or approved by the Commission E. It provides references to the journal and textbook literature, and for some entries, a listing of trade names and manufacturers. This new edition includes a section on nutritional supplements, and also provides a herb identification guide with photographs of plants and of herbal products.

DerMarderosian, Ara, and Beutler, John A. Review of Natural Products. 6th ed. St. Louis, Missouri: Facts and Comparisons, 2005. Available online from <http://www.statref.com>.

This title references the journal and book literature. It is a good source of information, although not as thorough as Natural Medicines Comprehensive Database.

Natural Medicines Comprehensive Database. 6th ed. Stockton, California: Therapeutic Research Faculty, 2004. Annual. Available online from <http://www. naturaldatabase.com>.

This is an extremely thorough title that provides information on safety and efficacy of herbals for many different uses. Every piece of information provided references the journal literature. This title also provides lists of ingredients for many brand name products. 


\section{WHICH SOURCES CONTAIN GOOD-QUALITY INFORMATION FOR THE LAYPERSON (OR INTERESTED LIBRARIAN)?}

The first two of these titles are best suited to those looking for information on specific drugs, while the latter two focus more on classes of drugs and how they have their effect.

USP Di Volume 2: Advice for the patient. 25th ed. Rockville, Maryland: United States Pharmacopeial Convention Inc., 2005. Also freely available from $<$ http://www.medlineplus.gov>.

Volume 2 of the USP Di provides brief, easy-to-understand descriptions of the use of each drug and its mechanism of action. Adverse effects, precautions to take when using the drug, and dosage information are also provided.

Raman-Wilms, Lalitha. Canadian Pharmacists Association Guide to Drugs in Canada. Toronto: Dorling Kindersley, 2004.

This is an excellent information source for patients and interested librarians (Canadian and otherwise). It begins with a section that explains how drugs work, followed by one-totwo-page descriptions of the major drug classes. This is followed by more specific one-page descriptions of 260 commonly-used drugs, both prescription and nonprescription. The strength of this guide is its highly visual nature; there are numerous diagrams, charts, and tables that make it easy to locate needed information (such as which adverse effects warrant a call to the doctor).

Iversen, Leslie L. Drugs: A Very Short Introduction. Oxford: Oxford University Press, 2001.

This is a pocket-sized and very readable book that gives a brief (130-page) overview of some of the major classes of drugs, drug development, recreational drugs, and how drugs work.

Stone, Trevor, and Darlington, Gail. Pills, Potions and Poisons: How Drugs Work. Oxford: Oxford University Press, 2004. 
This book provides a very interesting introduction to the major drugs grouped by therapeutic action. While there are diagrams and photographs, the print is small, and, at more than 400 pages, this is considerably more technical than Iversen's book.

\section{WHICH SOURCES CONTAIN FURTHER INFORMATION ON DRUG RESOURCES?}

Much more information on drug reference resources can be found in the following articles and books:

Adams, Mignon. "The Latest and the Best: Information Needs of Pharmacists." Science \& Technology Libraries 21, no. 3/4 (2001): 87-99.

Butros, Amy, and McGuinness, Susan. "Drug Information Sources.” In Introduction to Reference Sources in the Health Sciences. 4th ed., edited by J. A. Boorkman, J. T. Huber and F. W. Roper, 153-205. New York: Neal-Schuman, 2004.

Gleisner, Dorothy S. "Pharmacy Reference Sources: A Bibliography with Annotations." Reference Services Review 9(October/December, 1981): 37-49.

Malone, Patrick. Drug Information: A Guide for Pharmacists. 2nd ed. New York: McGrawHill, 2001.

Snow, Bonnie. Drug Information: A Guide to Current Resources. 2nd ed. Lanham, Maryland: Scarecrow Press, 1999. 